\title{
Abstract \\ Effect of Nanocellulose Type on the Properties of a Bio-Based Epoxy System ${ }^{\dagger}$
}

\author{
Marius-Stelian Popa ${ }^{1}$, Celina Maria Damian ${ }^{2}$, Brîndușa Bãlãnucã ${ }^{2}$, Denis Mihaela Panaitescu ${ }^{1}$ (D), \\ Augusta Raluca Gabor ${ }^{1}$, Cristian Andi Nicolae ${ }^{1}$, Valentin Rădiţoiu ${ }^{1} \mathbb{D}$, Monica Florentina Raduly ${ }^{1}(\mathbb{D})$ and \\ Adriana Nicoleta Frone ${ }^{1, *}$
}

Citation: Popa, M.-S.; Damian, C.M.; Bãlãnucã, B.; Panaitescu, D.M.; Gabor, A.R.; Nicolae, C.A.; Rădiţoiu, V.; Raduly, M.F.; Frone, A.N. Effect of Nanocellulose Type on the Properties of a Bio-Based Epoxy System. Chem. Proc. 2022, 7, 17. https://doi.org/ $10.3390 /$ chemproc2022007017

Academic Editors: Mihaela Doni, Florin Oancea, Zina Vuluga and Radu Claudiu Fierăscu

Published: 2 March 2022

Publisher's Note: MDPI stays neutral with regard to jurisdictional claims in published maps and institutional affiliations.

Copyright: (C) 2022 by the authors. Licensee MDPI, Basel, Switzerland. This article is an open access article distributed under the terms and conditions of the Creative Commons Attribution (CC BY) license (https:// creativecommons.org/licenses/by/ $4.0 /)$.
1 Polymer Department, National Institute for Research \& Development in Chemistry and Petrochemistry-ICECHIM, 011061 Bucharest, Romania; popamarius7777@gmail.com (M.-S.P.); panaitescu@icechim.ro (D.M.P.); raluca.gabor@icechim.ro (A.R.G.); cristian.nicolae@icechim.ro (C.A.N.); vraditoiu@icechim.ro (V.R.); monica.raduly@icechim.ro (M.F.R.)

2 Advanced Polymer Materials Group, University Politehnica of Bucharest, 011061 Bucharest, Romania; celina.damian@upb.ro (C.M.D.); brindusa.balanuca@upb.ro (B.B.)

* Correspondence: adriana.frone@icechim.ro

+ Presented at the 17th International Symposium "Priorities of Chemistry for a Sustainable Development" PRIOCHEM, Bucharest, Romania, 27-29 October 2021.

\begin{abstract}
With the continuous depletion of fossil oils and resulting environmental concerns, there is an urgent need to develop polymeric materials from renewable resources [1,2]. Epoxy resins are thermoset polymers that are recognized for their tunable properties (adhesiveness, tensile and electrical strength, stiffness, heat and chemical resistance) and for their various industrial and domestic applications. Still, the main drawback of epoxy resin is its brittleness. Thus, the addition of functional vegetable oils, such as epoxidized linseed oil (ELO), can improve the toughness of epoxy resin, while increasing the bio-based content of the final materials [1]. The goal of this work is to study the influence of composition, cross-linking conditions, and addition of reinforcing agents on the properties of a bio-based epoxy resin, obtained from epoxidized linseed oil (ELO), and a commercial hardener. Nanocellulose from common sources (microcrystalline cellulose MC) and agro-industrial residues (plum seeds shells-SC) were used as fillers in the epoxy-systems. Epoxidized linseed oil (ELO, TRAQUISA, Barcelona, Spain), Epilox-Hardener H 10-30 (G) (NANOCHEM, București, Romania), microcrystalline cellulose (MC) $(20 \mu \mathrm{m}$, Aldrich, St. Louis, MO, USA) and plum seed cellulose (SC) (laboratory obtained via acidic hydrolysis) were used as raw materials. A 2/1 weight ratio of ELO/G was used to obtain the cross-linked materials. Two types of cellulosic modifiers, $\mathrm{MC}$ and SC, were used to reinforce the epoxy systems. The resulted epoxy composite systems were characterized by means of FT-IR, TGA, DMA and water contact angle analysis. TGA analysis showed that the onset and maximum degradation temperatures were increased upon employing an extra cross-linking step at $140{ }^{\circ} \mathrm{C}$ or by addition of the cellulosic fillers. Moreover, an increase in the storage modulus of the final epoxy systems was attained as a result of the addition of cellulosic filler, as seen in the DMA results. The addition of a low-weight percentage $(0.5 \%)$ of cellulose modifiers (MC and SC) enhanced the thermal stability of the epoxy system and had a reinforcing effect by increasing the storage modulus of the final materials.
\end{abstract}

Keywords: nanocellulose; epoxidized linseed oil; thermal properties

Author Contributions: Methodology, M.-S.P.; Investigation, C.M.D.; Formal analysis, B.B., A.R.G., C.A.N., V.R., M.F.R.; Writing—review \& editing, D.M.P.; Conceptualization, Funding acquisition, A.N.F. All authors have read and agreed to the published version of the manuscript.

Funding: This work was supported by a grant of the Ministry of Research, Innovation and Digitization, CNCS/CCCDI-UEFISCDI, project number PN-III-P2-2.1-PED-2019-5002, no. 530/PEDEPOCEL, within PNCDI III. 
Institutional Review Board Statement: Not applicable.

Informed Consent Statement: Not applicable.

Data Availability Statement: Not applicable.

Conflicts of Interest: The authors declare no conflict of interest.

\section{References}

1. Di Mauro, C.; Malburet, S.; Genua, A.; Graillot, A.; Mija, A. Sustainable Series of New Epoxidized Vegetable Oil- Based Thermosets with Chemical Recycling Properties. Biomacromolecules 2020, 21, 3923-3935. [CrossRef] [PubMed]

2. Tang, Q.; Chen, Y.; Gao, H.; Li, Q.; Xi, Z.; Zhao, L.; Peng, C.; Li, L. Soybean-Biomass, Yield and Productivity; Kasai, M., Ed.; IntechOpen Limited: London, UK, 2019. 